\title{
Acquired Factor XIII Deficiency in a Patient with Metastatic Lung Cancer
}

\author{
Ana Sofia Mendes *,Marco Dias, Sara Morais, Raque, Romão, Bernardo Teixeira, Cláudia Pedrosa, Isa Peixoto, Paula Fidalgo, António \\ Araújo \\ Centro Hospitalar Universitário do Porto, 4099-001 Porto, Portugal
}

*Corresponding Author: Ana Sofia Mendes, Centro Hospitalar Universitário do Porto, 4099-001 Porto, Portugal.

Received Date: September 15, 2021 | Accepted Date: December 21, 2021| Published Date: January 01, 2022

Citation: Ana S Mendes, M Dias, S Morais, Raque, Romão, et al. (2022). Acquired Factor XIII Deficiency in a Patient with Metastatic Lung Cancer. Clinical Oncology Research and Reports. 3(1); DOI: 10.31579/2693-4787/028

Copyright: (C) 2022 Ana Sofia Mendes. This is an open-access article distributed under the terms of the Creative Commons Attribution License, which permits unrestricted use, distribution, and reproduction in any medium provided the original author and source are credited.

\begin{abstract}
Acquired factor XIII (FXIII) deficiency can result in life-long bleeding tendency and can be caused by enhanced consumption, impaired synthesis, or as an immune-mediated process. The latter can be related with solid neoplasms, through neutralizing or non-neutralizing antibodies. The relationship between FXIII activity and non-small cell lung cancer (NSCLC) is not well established. This case report is about a patient with NSCLC and acquired FXIII deficiency.

Materials and Methods: Clinical records were obtained through the electronic process analysis, and the confidentiality of the patient was always assured.

Results and Discussion: A 70-year-old male with no relevant past medical history and a recently diagnosed metastatic NSCLC was admitted for priapism. Five days later, a he developed a bleeding disorder, with slightly elevated coagulation times and normal fibrinogen levels and platelets count. FXIII level was found to be decreased $(0.24 \mathrm{IU} / \mathrm{mL})$ and FXIII plasma mixing studies did not confirm the presence of a neutralizing inhibitor. The FXIII level correction with standard plasma mixing studies was in favour of a non-neutralizing antibody. Despite treatment, haemorrhage control was not achieved and the patient died.
\end{abstract}

Conclusion: This clinical report describes a rare case of a patient with metastatic NSCLC presenting a severe haemorrhagic event caused by FXIII deficiency immune-mediated by non-neutralizing antibodies and subsequent increased clearance.

Keywords: Metastatic Lung Cancer; plasma; haemorrhage; comorbidities.

\section{Introduction}

Factor XIII (FXIII) is a pro-coagulant plasma protein, essential in the primary stabilization of the clot by cross-linking fibrin strands [1]. Its deficiency, resulting from inherited or acquired causes, can result in lifelong bleeding tendency [2]. Acquired FXIII deficiency can occur secondary to either enhanced consumption, impaired synthesis, or as an immune-mediated process [3]. It usually occurs in elderly patients, with a median age of 70 years, and may be related to comorbidities such as solid neoplasms [4, 5]. When this disorder is related to solid neoplasms, the underlying aetiology is usually immune-mediated either through inhibitory antibodies (neutralizing) or accelerated clearance (non-neutralizing antibodies) [6].

The relationship between FXIII and non-small cell lung cancer (NSCLC) is controversial, with some authors describing an increased activity of FXIII in such cases [7, 8].

This is a case report of a male patient with metastatic NSCLC and FXIII deficiency, which is a challenging diagnosis that requires a high index of clinical suspicion in the presence of normal routine coagulation tests (APTT, PT and fibrinogen).

\section{Materials and Methods}

Case report of a man with metastatic NSCLC and a haemorrhagic pattern due to FXIII deficiency. Clinical records were obtained through the electronic process analysis, and the confidentiality of the patient was always assured.

\section{Results and Discussion}

We describe a case of a 70-year-old male with a good performance status and a past medical history of arterial hypertension, post-traumatic stress disorder and prior smoking history. He had no personal or family history of haemorrhagic or haematologic disorders.

The patient was previously evaluated at another institution due to pain in the right buttock, radiating along the ipsilateral lower limb. Computed tomography (CT) scan revealed a lytic lesion on the right ischiopubic ramus associated with a pathological bone fracture. A biopsy of the lesion 
was performed, and histopathological and immunohistochemistry analysis identified a non-small cell carcinoma, adenosquamous type. Chest CT confirmed the presence of a subpleural pulmonary nodule in the upper segment of the right lower lobe, suspicious of primary lung cancer, as well as mediastinal enlarged lymph nodes.

Three months later he was admitted at our institution due to a one weeklong cryptogenic ischemic priapism, causing an acute urinary retention, with fever and increased inflammatory parameters. He was referred for an observation by Urology, who performed a corporal aspiration and irrigation, with complete detumescence. A broad-spectrum antibiotic was initiated.

The pelvic CT performed at admission showed the presence of multiple large lymph nodes (right iliac and obturator), the known lytic lesion with soft tissue involvement infiltrating the ipsilateral obturator muscle and a pelvic collection with a necrotic centre suggestive of superinfection.

After 5 days of hospitalization, the patient developed an extensive left lumbar haematoma, associated with significant haemoglobin decrease $(3 \mathrm{~g} / \mathrm{dL})$ and hemodynamic instability. The study revealed a slightly elevated activated partial thromboplastin time (aPTT) (32.3s) and prothrombin time (16.8s), without alterations in fibrinogen levels (2.25 $\mathrm{g} / \mathrm{L})$ or platelets count $(215000 / \mu \mathrm{L})$. After 48 hours, mucocutaneous bleeding increased and a newly performed $\mathrm{CT}$ scan revealed de novo multiple intra-pelvic and right thigh haematomas. At this time, coagulation and platelet study was repeated and no significant alterations were observed. Due to the bleeding progression in a patient with a NSCLC and minimal changes on routine screening coagulation tests, the suspicion of FXIII deficiency was raised. A FXIII level was found to be decreased $(0.24 \mathrm{IU} / \mathrm{mL})$ and FXIII plasma mixing studies did not confirm the presence of a neutralizing inhibitor $[9,10]$. The patient immediately started FXIII supplementation with fresh frozen plasma and intravenous prednisolone $1 \mathrm{mg} / \mathrm{kg} / \mathrm{day}$, but died within 24 hours. Given the patient's recent cancer diagnosis and this bleeding condition, therapy directed to the oncological disease was never initiated.

An unrecognized coagulation disorder can have serious consequences. The differential diagnosis of a bleeding disorder with normal coagulation testing are limited but challenging. FXIII deficiency, as shown in our case report, is one of those diagnosis.

Causes of FXIII deficiency, other than congenital, can be either immune (through inhibitory antibodies - neutralizing, or accelerated clearance non-neutralizing antibodies) or non-immune mediated (reduced synthesis or increased consumption) [3]. In the present case, congenital FXIII coagulation deficiency was ruled out, based on patient's age and absence of personal or familiar history of bleeding tendency.

When FXIII levels are lower than $10 \%$, the cause is usually immunemediated, and patients present with significant bleeding symptoms. At superior levels, the bleeding tends to be milder and the cause non-immune mediated. If the aetiology of the disorder is a solid neoplasm, the most likely pathophysiology will be immune-mediated [6]. The treatment of the immune-mediated cause involves high-dose corticosteroids and/or cyclophosphamide [11] and the treatment of the bleeding event involves replacement of FXIII through concentrate, cryoprecipitate, or fresh frozen plasma [12]. The FXIII level correction with standard plasma mixing studies was in favour of a non-neutralizing antibody.

Coagulation abnormalities are common in patients with metastatic oncological disease [13]. The relationship between FXIII and NSCLC is controversial, with some authors describing an increased activity of FXIII in patients with this neoplasm [7,8]. Given the initial picture of priapism in a patient with NSCLC, there was a suspicion of disseminated intravascular coagulation (DIC). Nevertheless, the APTT and PT were only slightly elevated, and the fibrinogen and platelet counts were normal and stable over time, which argues against DIC.

To the best of our knowledge, this is the first reported case of acquired FXIII deficiency in a patient with metastatic NSCLC.

\section{Conclusion}

Many patients with metastatic solid neoplasms have coagulation study abnormalities. Acquired FXIII deficiency is a rare condition and in cancer patients it is usually immune-mediated. This report represents a rare case of a patient with metastatic NSCLC and a severe haemorrhagic event caused by FXIII deficiency immune-mediated by non-neutralizing antibodies and subsequent increased clearance.

\section{References}

1. Muszbek L, Bereczky Z, Bagoly Z, Komáromi I, Katona É. (2011). Factor XIII: a coagulation factor with multiple plasmatic and cellular functions. Physiol Rev. 91(3):931-972.

2. Dorgalaleh A, Naderi M, Hosseini MS, Alizadeh S, Hosseini S, Tabibian S, et al. (2015). Factor XIII deficiency in Iran: a comprehensive review of the literature. Semin Thromb Hemost. 41(3):323-329.

3. Schroeder V, Kohler HP. (2013). Factor XIII deficiency: an update. Semin Thromb Hemost. 39(6):632-641.

4. Yan MTS, Rydz N, Goodyear D, Sholzberg M. (2018). Acquired factor XIII deficiency: A review. Transfus Apher Sci. 57(6):724730.

5. Ichinose A, (2017). Japanese Collaborative Research Group on AH13. Autoimmune acquired factor XIII deficiency due to antifactor XIII/13 antibodies: A summary of 93 patients. Blood Rev. 31(1):37-45.

6. Ichinose A, Kohler HP, Philippou H. (2016). Factor XIII and Fibrinogen SSC Subcommittee of the ISTH. Recommendation for ISTH/SSC Criterion 2015 for autoimmune acquired factor XIII/13 deficiency. Thromb Haemost. 116(4):772-774.

7. Lee SH, Suh IB, Lee EJ, Hur GY, Lee SY, Lee SY, et al. (2013). Relationships of coagulation factor XIII activity with cell-type and stage of non-small cell lung cancer. Yonsei Med J. 54(6):1394-1399.

8. Sawai Y, Yamanaka Y, Nomura S. (2020). Clinical Significance of Factor XIII Activity and Monocyte-Derived Microparticles in Cancer Patients. Vasc Health Risk Manag. 16:103-110.

9. Dorgalaleh A, Rashidpanah J. (2016). Blood coagulation factor XIII and factor XIII deficiency. Blood Rev. 30(6):461-475.

10. Kohler HP, Ichinose A, Seitz R, Ariens RA, Muszbek L. (2011). Factor XIII and Fibrinogen SSC Subcommittee of the ISTH. Diagnosis and classification of factor XIII deficiencies. J Thromb Haemost. 9(7):1404-1406.

11. Franchini M, Frattini F, Crestani S, Bonfanti C. (2013). Acquired FXIII inhibitors: a systematic review. J Thromb Thrombolysis. 36(1):109-114.

12. Caudill JS, Nichols WL, Plumhoff EA, Schulte SL, Winters JL, Gastineau DA, et al. (2009). Comparison of coagulation factor XIII content and concentration in cryoprecipitate and fresh-frozen plasma. Transfusion. 49(4):765-770.

13. Wang X, Wang E, Kavanagh JJ, Freedman RS. (2005). Ovarian cancer, the coagulation pathway, and inflammation. J Transl Med. $3: 25$. 
This work is licensed under Creative Commons Attribution 4.0 License

To Submit Your Article Click Here:

Submit Manuscript

DOI: $10.31579 / 2693-4787 / 028$
Ready to submit your research? Choose Auctores and benefit from:

* fast, convenient online submission

* rigorous peer review by experienced research in your field

* rapid publication on acceptance

- authors retain copyrights

* unique DOI for all articles

* immediate, unrestricted online access

At Auctores, research is always in progress.

Learn https://auctoresonline.org/journals/clinical-oncology-researchand-reports 